\title{
Quantitation of all Four Gardnerella vaginalis Clades Detects Abnormal Vaginal Microbiota Characteristic of Bacterial Vaginosis More Accurately than Putative G. vaginalis Sialidase A Gene Count
}

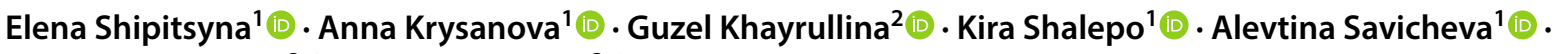 \\ Alexander Guschin $^{2}$ (D) Magnus Unemo ${ }^{3}$
}

Published online: 5 February 2019

(c) The Author(s) 2019

\begin{abstract}
Background Bacterial vaginosis (BV) is a vaginal disorder characterized by a depletion of the normal lactobacillus-dominant microbiota and overgrowth of mainly anaerobic bacteria.

Objectives The study aimed to evaluate the distribution and abundance of the Gardnerella vaginalis clades and sialidase A gene in vaginal samples from Russian women, and investigate if the G. vaginalis sialidase A gene count detects an abnormal vaginal microbiota characteristic of BV more accurately than G. vaginalis load.

Methods Vaginal samples from 299 non-pregnant patients of gynecological clinics were examined using Nugent scores and G. vaginalis clade and sialidase A gene quantitative real-time polymerase chain reactions (PCRs). Discriminatory power for BV microbiota was evaluated with receiver operating characteristic (ROC) analysis.

Results The vaginal microbiota was characterized by Nugent scores as normal, intermediate, and BV microbiota in 162, 58, and 79 women, respectively. G. vaginalis clades 1, 2, 3, 4, and the sialidase A gene were detected in 56\% (51-62\%), 40\% (34-45\%), 20\% (16-25\%), 94\% (91-96\%), and 70\% (64-75\%) of vaginal samples, respectively. The frequency and abundance of clades 1,2, 4, and the sialidase A gene as well as clade multiplicity were significantly associated with abnormal microbiota. The sialidase A gene was present in all multi-clade samples, in all single-clade samples comprising clades 1, 2, and 3, and in four of $84(5 \%$ [2-12\%]) samples comprising clade 4 only. Total G. vaginalis load showed significantly higher discriminatory power for abnormal microbiota than sialidase A gene count (areas under ROC curves 0.933 vs. $0.881 ; p=0.0306$ ).

Conclusions Quantifying all four G. vaginalis clades discriminates between BV microbiota and normal microbiota more accurately than measuring G. vaginalis sialidase A gene. Clade 4 is strongly associated with BV microbiota, despite most clade 4 strains lacking the sialidase A gene.
\end{abstract}

Magnus Unemo

magnus.unemo@regionorebrolan.se

1 Laboratory of Microbiology, D.O. Ott Research Institute of Obstetrics, Gynaecology and Reproductology, 3 Mendeleyevskaya Lane, 199034 St. Petersburg, Russia

2 Laboratory of Molecular Diagnostics and Epidemiology of Reproductive Tract Infections, Federal Budget Institute of Science "Central Research Institute for Epidemiology", 3a Novogireyevskaya St, 111123 Moscow, Russia

3 WHO Collaborating Centre for Gonorrhoea and other STIs, Department of Laboratory Medicine, Microbiology, Örebro University Hospital, Södra Grevrosengatan 2, 70185 Örebro, Sweden

\section{Key Points}

High Gardnerella vaginalis overall load predicts abnormal vaginal microbiota characteristic of bacterial vaginosis (BV) better than high sialidase A gene counts.

Although G. vaginalis clade 4 strains appear to lack the sialidase A gene, it is strongly associated with BV microbiota. 


\section{Introduction}

Bacterial vaginosis (BV) is a vaginal disorder characterized by a depletion of the normal lactobacillus-dominant microbiota and overgrowth of mainly anaerobic bacteria, i.e., an abnormal vaginal microbiota. Clinically, BV is manifested as abnormal malodorous vaginal discharge, but an abnormal vaginal microbiota characteristic of BV can be detected also in asymptomatic individuals [1]. BV is associated with an increased risk of many gynecological and obstetrical complications [2-5]. Gardnerella vaginalis is a common bacterial species in the vaginal microbiota and can be found in many healthy women. However, it is substantially more abundant and nearly ubiquitous in women with BV $[6,7]$. G. vaginalis is considered to play a key role in the pathogenesis of $\mathrm{BV}$, being an initial colonizer of the vaginal epithelium due to the higher adhesion, cytotoxicity, and greater propensity to form biofilm (compared to other BV-associated bacteria), and acting as a scaffold to which other species subsequently can attach [8-10].

Gardnerella vaginalis is a phenotypically and genetically heterogeneous species [11-17]. Eight metabolic biotypes of $G$. vaginalis were identified early based on the presence of $\beta$-galactosidase, lipase, and hippurate hydrolysis activities [11], and 17 biotypes based on these characteristics and additionally on utilization of xylose, arabinose, and galactose [12]. Phenotypic diversity within the $G$. vaginalis species has also been shown in relation to virulence factors, such as production of sialidase and vaginolysin, initial adhesion, cytotoxic effect, biofilm formation, susceptibility to antimicrobials, and the ability of G. vaginalis to displace lactobacilli adhered to HeLa cells [18-22]. Association of G. vaginalis biotypes with BV has been evaluated in a number of studies, but the results have been contradictory $[11,19,20,23-25]$. Sialidase is utilized by some BV-associated bacteria, including G. vaginalis, for degradation and depletion of protective host mucus barriers [26, 27]. Detection of the BV virulence factor sialidase has also been used in rapid point-of-care tests for BV, e.g., BVBlue ${ }^{\circledR}$ (Sekisui Diagnostics, L.L.C., Birmingham, AL, USA) [28].

Genetic heterogeneity within the G. vaginalis species has been demonstrated using molecular approaches, such as amplified ribosomal DNA restriction analysis (ARDRA) [13]. Using this method, three distinct $G$. vaginalis genotypes were identified, of which two produced sialidase. Although a link with sialidase production was shown for particular G. vaginalis ARDRA genotypes [18, 20], no clear association between BV and any of the ARDRA genotypes has been identified [18]. Different genetic variants of $G$. vaginalis based on a comparative genomic analysis have been described, and evidence of substantial differences in metabolic and virulence potential between G. vaginalis clinical strains has been reported [14, 15].

More recently, detailed genomic analyses [16] have identified four main clades within the G. vaginalis species. There were substantial differences in genome size, GC ratio, and core gene content between the clades, suggesting a possibility of considering them as separate bacterial species. Four subgroups of $G$. vaginalis (subgroups A-D), based on sequencing of a region of the chaperonin-60 (cpn60) gene, have also been proposed to represent different species [17]. Subsequently, G. vaginalis clades 1-4 were reconciled with cpn60 subgroups A-D [29]: cpn60 subgroup A corresponded to clade 4 , subgroup B to clade 2 , subgroup C to clade 1 , and subgroup D to clade 3 . In the same study [29], presence and activity of the putative sialidase A gene were investigated in G. vaginalis isolates. All isolates of subgroups B, C, and D, but only one (3\%) of the subgroup A isolates, possessed the putative sialidase A gene, while sialidase activity was displayed by all isolates of subgroup B, three (9\%) subgroup C isolates, and none of the isolates of subgroups $\mathrm{A}$ and $\mathrm{D}$, suggesting that this gene is not expressed (or not constitutively expressed) in many isolates. An association of the G. vaginalis sialidase A gene, as a proxy for sialidase production, with biofilm on the vaginal epithelium and with BV was subsequently examined [30]. The sialidase A gene was detected in $75 \%$ of G. vaginalispositive vaginal samples, and there was a strong association between high counts of the G. vaginalis sialidase A gene, the presence of $G$. vaginalis biofilm, and BV [30]. These observations indicate distinct clinical and diagnostic relevance of G. vaginalis subgroups/clades for BV.

The objectives of this study were to evaluate the distribution and abundance of the G. vaginalis clades, corresponding to the cpn60 subgroups, and putative sialidase A gene in vaginal samples from Russian women with normal and BV microbiota, and to investigate if $G$. vaginalis sialidase A gene counts can detect an abnormal microbiota characteristic of BV more accurately than $G$. vaginalis bacterial load.

\section{Materials and Methods}

\subsection{Patients, Specimens and Bacterial Vaginosis Diagnosis}

The study subjects were women of reproductive age (from 18 to 54 years) who attended gynecological clinics in St Petersburg, Russia with vaginal symptoms (mainly abnormal vaginal discharge) from October to December 2015. The exclusion criteria were pregnancy and taking oral or intravaginal antimicrobials within the last month. 
Vaginal samples were collected using two Dacron ${ }^{\circledR}$ swabs. One vaginal swab was used for preparing a microscopic slide, which was Gram stained and analyzed microscopically for bacterial morphotypes according to the Nugent scores [31]. The other vaginal swab was placed into $0.5 \mathrm{~mL}$ of buffered saline solution supplemented with mucolytic, preservative, and stabilizing agents (Transport Medium with Mucolytic Agent, InterLabService, Moscow, Russia) and used for polymerase chain reaction (PCR) detection of the $G$. vaginalis clades and the putative $G$. vaginalis sialidase A gene.

\subsection{Quantitative Polymerase Chain Reaction (PCR) Detection of the Gardnerella vaginalis Clades and the Putative G. vaginalis Sialidase A Gene}

The detection of the four clades of G. vaginalis [16] was performed using a multiplex real-time PCR assay with previously described primers and probes [32]. Real-time PCR analysis of the G. vaginalis sialidase A gene was performed using the forward primer GVSI forward (5'-GACGACGGC GAATGGCACGA-3'), designed by Santiago et al. [18], and the newly designed reverse primer GvSia1R2 (5'-GCTGTA TCCGTCTACGTAAATG-3') and TaqMan ${ }^{\circledR}$ probe GvSia1Z2r (5'-R6G-CTCCGCGATTTGCGCGAATAATCBHQ1-3'). The design of the new oligonucleotides was based on the alignment of the sequence of the sialidase A gene from G. vaginalis American Type Culture Collection (ATCC) 14019 (National Center for Biotechnology Information [NCBI] reference sequence: NC_014644.1 [https:// www.ncbi.nlm.nih.gov/nuccore/NC_014644.1]), used by Santiago et al. [18], and corresponding sequences of other G. vaginalis strains (belonging to different clades), described in the study by Ahmed et al. [16]. In this sequence alignment, the previously used reverse primer GVSI [18] had two mismatches at the 3'-end in some strains, which could reduce the sensitivity of detecting some $G$. vaginalis strains. A new TaqMan ${ }^{\circledR}$ hybridization probe specific for the conservative part of the chosen fragment was also designed to enable accurate, sensitive, and specific detection. Specificity of the newly designed primer and probe was verified using Standard Nucleotide BLAST ${ }^{\circledR}$ (Basic Local Alignment Search Tool) software (NCBI; https://blast.ncbi.nlm.nih.gov/Blast .cgi).

DNA for both PCR assays was isolated from $100 \mu \mathrm{L}$ of sample using the silica-based manual extraction kit DNASorb-AM (InterLabService, Moscow, Russia), according to the manufacturer's instructions, with an elution volume of $100 \mu \mathrm{L}$. The DNA preparations were stored at $4{ }^{\circ} \mathrm{C}$ prior to amplification, which was performed within 3 days.

PCR amplifications were performed in reactions $(25 \mu \mathrm{L})$ containing $10 \mu \mathrm{L}$ of Mix-1 $(0.7 \mathrm{pmol} / \mu \mathrm{L}$ of each primer, $0.2 \mathrm{pmol} / \mu \mathrm{L}$ of each probe, $0.44 \mathrm{mM}$ deoxyribonucleotide triphosphates (dNTPs), $0.1 \mathrm{mM}$ Tris, and $0.1 \mathrm{mM}$ EDTA), $5 \mu \mathrm{L}$ of Mix-2 (20\% glycerol, $0.17 \mathrm{M}$ Tris- $\mathrm{HCl}$ (pH 8.3), $42 \mathrm{mM}\left(\mathrm{NH}_{4}\right)_{2} \mathrm{SO}_{4}, 0.025 \%$ Tween-20, $7.5 \mathrm{mM} \mathrm{MgSO}$, $0.25 \mathrm{mg} / \mathrm{mL}$ of bovine serum albumin (BSA), $0.02 \%$ xylenethanol, $0.125 \%$ sodium azide, $0.5 \mathrm{U} / \mu \mathrm{L}$ of Taq-polymerase), and $10 \mu \mathrm{L}$ of DNA template. The PCR program parameters were as follows: $95^{\circ} \mathrm{C}$ for 15 min followed by 40 cycles of $95{ }^{\circ} \mathrm{C}$ for $15 \mathrm{~s}, 60{ }^{\circ} \mathrm{C}$ for $20 \mathrm{~s}$, and $72{ }^{\circ} \mathrm{C}$ for $15 \mathrm{~s}$, with fluorescence read at $60{ }^{\circ} \mathrm{C}$. All PCR amplifications were performed on a Rotor-Gene Q instrument (QIAGEN, Hilden, Germany). Negative controls (sterile nucleic acidfree water) were included in each run.

For quantification of PCR-amplified fragments, quantitative standard samples were constructed by cloning PCR fragments of the targeted genes into $\mathrm{pGEM}^{\circledR}$-T Vector Systems (Promega, Madison, USA). DNA concentration of plasmid preparations was tested using digital PCR with the same specific primers and probes on a QX100 ${ }^{\mathrm{TM}}$ Droplet Digital ${ }^{\mathrm{TM}}$ PCR System (BioRad, Hercules, CA, USA). Standard curves were generated by testing quantitative standard samples (in duplicate) in concentrations of $10^{3}, 10^{5}, 10^{7}$, and $10^{9}$ genome equivalents (geqs) $/ \mathrm{mL}$ for all targets. Concentrations in the clinical samples were expressed as geqs $/ \mathrm{mL}$ of DNA extract.

\subsection{Statistical Analyses}

Based on the Nugent scores, all women were divided into three groups, i.e., women with normal vaginal microbiota (a score of 0-3), intermediate microbiota (4-6), and BV microbiota (7-10) [31]. Categorical variables (the presence of the G. vaginalis clades and sialidase A gene and the presence of multiple $G$. vaginalis clades) were evaluated using Pearson's Chi squared test for all three groups of patients, with Cramer's $V$ coefficient measured to evaluate the strength of association, which was followed by pairwise comparisons using Fisher's exact test. Continuous data (the loads of the G. vaginalis clades and sialidase A gene), after being characterized as not normally distributed in the Shapiro-Wilk test, were analyzed using the Kruskal-Wallis test for all three groups followed by post hoc pairwise comparisons using Dunn's multiple comparisons test. All percentages were reported with 95\% confidence intervals (CIs), computed with the use of Wilson's method with Brown's modification. To assess the ability to differentiate between samples with normal and abnormal vaginal microbiota using total G. vaginalis DNA load, G. vaginalis clades and sialidase A gene counts, receiver operating characteristic (ROC) curves were plotted, and classification performance characteristics (areas under the curves [AUCs], as well as true positive proportion [sensitivity], true negative proportion [specificity], and Youden's index in optimum points) were computed. Differences between AUC values were assessed using the DeLong method. Statistical analyses were performed with 
the use of the statistical packages GraphPad Prism version 7.04 for Windows (GraphPad Software, San Diego, CA, USA) and Analyse-It for Microsoft Excel 5.11 (Analyse-it Software, Leeds, UK). All tests for significance were twosided, and statistically significant differences were assumed when $p<0.05$.

\section{Results}

In total, 299 women aged 18-54 years (median age 30 years; mean age 32 years) were enrolled in the study. The vaginal microbiota was characterized as normal in 162 women (median age 29 years), intermediate in 58 (median age 31 years), and BV microbiota in 79 (median age 30 years). G. vaginalis DNA was detected in 288 women: 151 women with normal microbiota and in all women with intermediate microbiota and abnormal microbiota (Table 1). The most prevalent $G$. vaginalis clade was clade 4 (94\% [91-96\%]), followed by clades 1 (56\% [51-62\%]), 2 (40\% [34-45\%]), and 3 (20\% [16-25\%]). The G. vaginalis sialidase A gene was detected in 208 women (70\% [64-75\%]). Clades 1, 2, and 4 and the sialidase A gene were significantly associated with BV microbiota (Table 1).

Loads of $G$. vaginalis clades 1, 2, and 4 as well as total G. vaginalis load and sialidase A gene counts were significantly higher in intermediate microbiota than in normal microbiota, in abnormal versus intermediate, and in abnormal versus normal samples. For clade 3, no difference was observed between loads in abnormal versus normal and in abnormal versus intermediate samples (Table 2).

Of the $288 G$. vaginalis-positive women, $89(31 \%$ [26-36\%]) harbored a single clade and $199(69 \%$ [64-74\%]) multiple clades (two or more). Multiple clades were detected significantly more often in abnormal than in intermediate microbiota (odds ratio [OR] 0.234; $p=0.0019$ ) and in abnormal than in normal microbiota (OR 0.163; $p<0.0001)$. No significant difference between normal and intermediate microbiota was observed (OR 0.701; $p=0.3416$ ) (Fig. 1).

The large majority ( 84 of $89 ; 94 \%$ [88-98\%]) of the single-clade samples contained clade 4 , with 57 samples obtained from women with normal microbiota, 19 samples from women with intermediate microbiota, and eight samples from women with BV microbiota. The remaining five samples contained clades $1(n=3), 2(n=1)$, and $3(n=1)$, with all of them obtained from women with normal microbiota. The sialidase A gene was present in all single-clade samples comprising clades 1,2 , and 3 and in 4 (5\% [2-12\%]) single-clade samples comprising clade 4: two samples with normal microbiota and two samples with intermediate microbiota. In all multi-clade samples, the sialidase A gene was present.

With the use of ROC analysis, we evaluated the usefulness of DNA counts of the $G$. vaginalis clades and putative sialidase A gene for distinguishing BV microbiota from normal microbiota (Fig. 2). Total G. vaginalis load possessed a superior discriminatory power (AUC 0.933), followed by the counts of the sialidase A gene (AUC 0.881), clade 4 (AUC 0.857), clade 1 (AUC 0.827), and clade 2 (AUC

Table 1 Frequency of the Gardnerella vaginalis clades and sialidase A gene in women with normal microbiota, intermediate microbiota, and abnormal vaginal microbiota characteristic of bacterial vaginosis

\begin{tabular}{|c|c|c|c|c|c|c|c|c|}
\hline \multirow[t]{2}{*}{ Clade/gene } & \multicolumn{4}{|c|}{ Frequency $(\%[95 \% \mathrm{CI}])$} & \multirow{2}{*}{$\begin{array}{l}\text { Pearson's Chi } \\
\text { squared test: } \\
\text { Chi square } \\
\text { statistic; } \\
\text { Cramer's } V \\
\text { coefficient ( } p \\
\text { value) }\end{array}$} & \multicolumn{3}{|c|}{ Fisher's exact test: OR ( $p$ value) } \\
\hline & $\begin{array}{l}\text { All women } \\
(n=299)\end{array}$ & $\begin{array}{l}\text { Women with } \\
\text { normal micro- } \\
\text { biota }(n=162)\end{array}$ & $\begin{array}{l}\text { Women with } \\
\text { intermediate } \\
\text { microbiota } \\
(n=58)\end{array}$ & $\begin{array}{l}\text { Women with } \\
\text { abnormal } \\
\text { microbiota } \\
(n=79)\end{array}$ & & $\begin{array}{l}\text { Normal vs. } \\
\text { intermediate }\end{array}$ & $\begin{array}{l}\text { Intermediate } \\
\text { vs. abnormal }\end{array}$ & $\begin{array}{l}\text { Normal vs. } \\
\text { abnormal }\end{array}$ \\
\hline Clade 1 & $\begin{array}{c}169(56 \\
[51-62])\end{array}$ & $\begin{array}{l}70(43 \\
[36-51])\end{array}$ & $\begin{array}{l}35(60 \\
[48-72])\end{array}$ & $\begin{array}{l}64(81 \\
[71-88])\end{array}$ & $\begin{array}{l}31.3 ; 0.324 \\
(<0.0001)\end{array}$ & $\begin{array}{l}0.502 \\
\quad(0.0318)\end{array}$ & $\begin{array}{l}0.360 \\
\quad(0.0116)\end{array}$ & $\begin{array}{l}0.180 \\
\quad(<0.0001)\end{array}$ \\
\hline Clade 2 & $\begin{array}{l}119(40 \\
[34-45])\end{array}$ & $\begin{array}{l}46(28 \\
[22-36])\end{array}$ & $\begin{array}{l}20(34 \\
[24-47])\end{array}$ & $\begin{array}{l}53(67 \\
[56-76])\end{array}$ & $\begin{array}{l}34.0 ; 0.337 \\
\quad(<0.0001)\end{array}$ & $\begin{array}{l}0.754 \\
\quad(0.4066)\end{array}$ & $\begin{array}{l}0.261 \\
\quad(0.0002)\end{array}$ & $\begin{array}{l}0.196 \\
\quad(<0.0001)\end{array}$ \\
\hline Clade 3 & $\begin{array}{l}59(20 \\
\quad[16-25])\end{array}$ & $\begin{array}{l}34(21 \\
\quad[15-28])\end{array}$ & $\begin{array}{l}12(21 \\
\quad[12-33])\end{array}$ & $\begin{array}{l}13(16 \\
[10-26])\end{array}$ & $\begin{array}{l}0.73 ; 0.049 \\
(0.6941)\end{array}$ & $\begin{array}{l}1.018 \\
(1.0000)\end{array}$ & $\begin{array}{l}1.322 \\
(0.6550)\end{array}$ & $1.347(0.4895)$ \\
\hline Clade 4 & $\begin{array}{l}282(94 \\
[91-96])\end{array}$ & $\begin{array}{l}145(90 \\
[84-93])\end{array}$ & $\begin{array}{l}58(100 \\
[94-100])\end{array}$ & $\begin{array}{l}79(100 \\
[95-100])\end{array}$ & $\begin{array}{l}15.2 ; 0.226 \\
(0.0005)\end{array}$ & $\begin{array}{l}0.000 \\
(0.0077)\end{array}$ & ND & $0.000(0.0010)$ \\
\hline Any clade & $\begin{array}{l}288(96 \\
[94-98])\end{array}$ & $\begin{array}{l}151(93 \\
[88-96])\end{array}$ & $\begin{array}{l}58(100 \\
\quad[94-100])\end{array}$ & $\begin{array}{l}79(100 \\
[95-100])\end{array}$ & $\begin{array}{r}9.7 ; 0.180 \\
(0.0080)\end{array}$ & $\begin{array}{l}0.000 \\
(0.0712)\end{array}$ & ND & $0.000(0.0179)$ \\
\hline $\begin{array}{l}\text { Sialidase A } \\
\text { gene }\end{array}$ & $\begin{array}{l}208(70 \\
[64-75])\end{array}$ & $\begin{array}{l}96(59 \\
[52-67])\end{array}$ & $\begin{array}{l}41(71 \\
[58-81])\end{array}$ & $\begin{array}{l}71(90 \\
[81-95])\end{array}$ & $\begin{array}{l}23.6 ; 0.281 \\
\quad(<0.0001)\end{array}$ & $\begin{array}{l}0.604 \\
\quad(0.1554)\end{array}$ & $\begin{array}{l}0.274 \\
\quad(0.0065)\end{array}$ & $\begin{array}{l}0.165 \\
\quad(<0.0001)\end{array}$ \\
\hline
\end{tabular}

$C I$ confidence interval, $N D$ not determined (because the frequency rates in the groups were the same), $O R$ odds ratio 
Table 2 Loads of the Gardnerella vaginalis clades and sialidase A gene in women with normal microbiota, intermediate microbiota, and abnormal vaginal microbiota characteristic of bacterial vaginosis

\begin{tabular}{|c|c|c|c|c|c|c|c|}
\hline \multirow[t]{2}{*}{ Clade/gene } & \multicolumn{3}{|c|}{ Median load (geqs/mL) } & \multirow{2}{*}{$\begin{array}{l}\text { Kruskal-Wallis } \\
\text { test: Kruskal- } \\
\text { Wallis statistic ( } p \\
\text { value) }\end{array}$} & \multicolumn{3}{|c|}{$\begin{array}{l}\text { Dunn's multiple comparisons test: mean rank difference } \\
\text { (adjusted } p \text {-value) }\end{array}$} \\
\hline & $\begin{array}{l}\text { Normal micro- } \\
\text { biota }\end{array}$ & $\begin{array}{l}\text { Intermedi- } \\
\text { ate micro- } \\
\text { biota }\end{array}$ & $\begin{array}{l}\text { Abnormal } \\
\text { microbiota }\end{array}$ & & $\begin{array}{l}\text { Normal vs. inter- } \\
\text { mediate }\end{array}$ & $\begin{array}{l}\text { Intermediate vs. } \\
\text { abnormal }\end{array}$ & $\begin{array}{l}\text { Normal vs. abnor- } \\
\text { mal }\end{array}$ \\
\hline Clade 1 & $1.8 \times 10^{3}$ & $2.1 \times 10^{4}$ & $1.1 \times 10^{7}$ & $66.3(<0.0001)$ & $-34.5(0.0020)$ & $-34.4(0.0025)$ & $-68.9(<0.0001)$ \\
\hline Clade 2 & $1.0 \times 10^{3}$ & $3.5 \times 10^{4}$ & $6.1 \times 10^{5}$ & $46.5(<0.0001)$ & $-22.3(0.0477)$ & $-25.1(0.0169)$ & $-47.3(<0.0001)$ \\
\hline Clade 3 & $5.1 \times 10^{2}$ & $2.3 \times 10^{3}$ & $2.0 \times 10^{3}$ & $7.5(0.0239)$ & $-14.0(0.0460)$ & $3.5(>0.9999)$ & $-10.5(0.1858)$ \\
\hline Clade 4 & $5.2 \times 10^{3}$ & $1.5 \times 10^{4}$ & $5.7 \times 10^{7}$ & $73.5(<0.0001)$ & $-38.5(0.0071)$ & $-59.2(<0.0001)$ & $-97.7(<0.0001)$ \\
\hline Any clade & $8.9 \times 10^{3}$ & $4.7 \times 10^{5}$ & $1.1 \times 10^{8}$ & $124.9(<0.0001)$ & $-60.1(<0.0001)$ & $-68.2(<0.0001)$ & $-128.4(<0.0001)$ \\
\hline Sialidase A gene & $3.0 \times 10^{3}$ & $1.7 \times 10^{5}$ & $3.0 \times 10^{7}$ & $100.4(<0.0001)$ & $-47.2(<0.0001)$ & $-47.0(0.0002)$ & $-94.2(<0.0001)$ \\
\hline
\end{tabular}

geqs genome equivalents
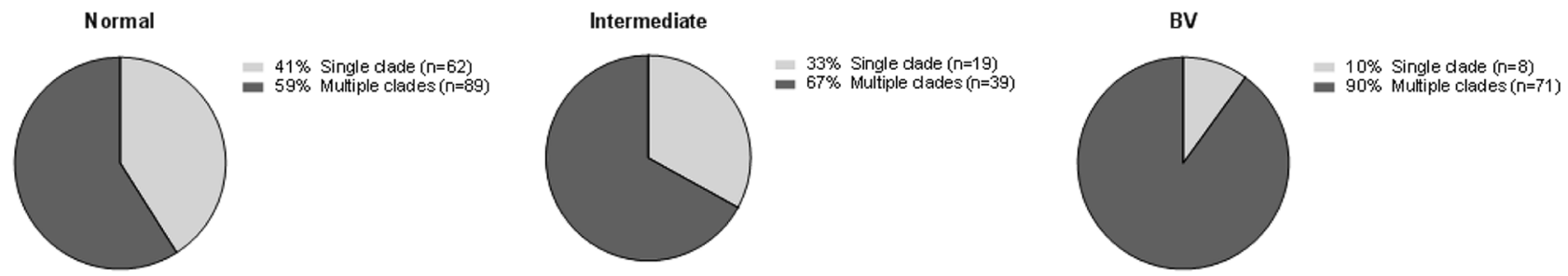

Fig. 1 Single versus multiple Gardnerella vaginalis clades in women with normal microbiota, intermediate microbiota, and abnormal vaginal microbiota characteristic of bacterial vaginosis (BV)

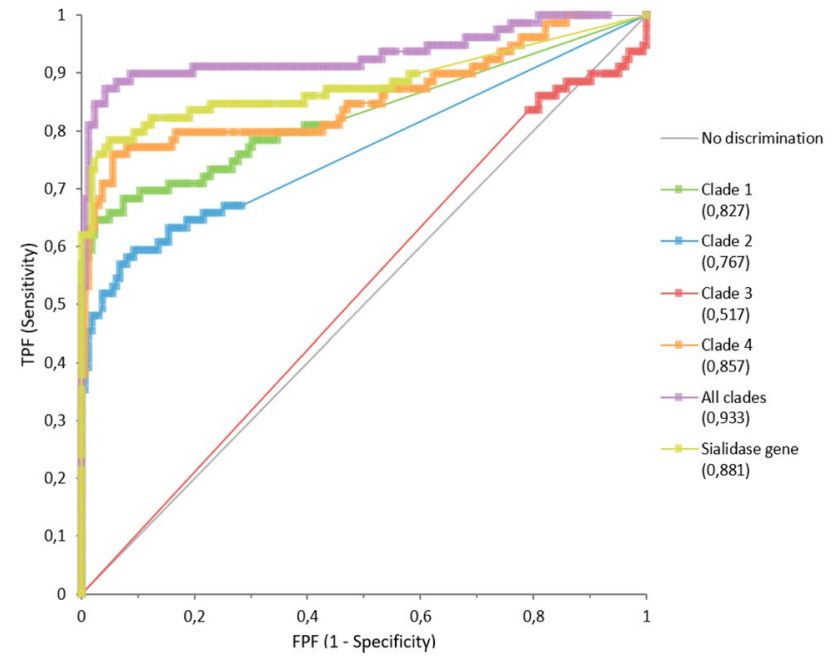

Fig. 2 Areas under the receiver operating characteristic curves (values provided in parentheses) for the Gardnerella vaginalis clades and sialidase A gene. FPF false positive fraction, $T P F$ true positive fraction

0.767). The clade 3 count, as expected, showed no discriminatory ability for BV microbiota (AUC 0.517). The AUC for sialidase A gene count significantly exceeded those for clade 1 and 2, showed no difference with that for clade 4 , and was significantly lower than that for total G. vaginalis load (Table 3).

\section{Discussion}

Since the four clades of $G$. vaginalis were described, several studies have investigated their association with BV. Balashov et al. [32] developed a real-time PCR assay for detection of the four clades in clinical vaginal samples and found positive correlations between BV and clades 1 and 3, but not clades 2 and 4 . The presence of multiple clades, which was detected in $70 \%$ of samples, was associated with BV. More recently, it was shown that clades 1 and 2 were significantly more common in BV samples (Nugent score 7-10), whereas clades 3 and 4 had no association with BV, and multi-clade G. vaginalis communities were associated with Nugent score $\geq 4$ [33]. In a recent cohort study [34], it was demonstrated that young women who developed BV were more likely to have clade 4 than those reporting no sex or who practiced noncoital activities. Furthermore, vaginal samples were more likely to contain multiple G. vaginalis clades rather than a single clade if women engaged in penile-vaginal sex or were diagnosed with BV. Hilbert et al. [35], studying G. vaginalis population dynamics in $\mathrm{BV}$, revealed a predominance 
Table 3 Classification performance characteristics of the Gardnerella vaginalis clades and sialidase A gene in receiver operating characteristic analysis

\begin{tabular}{|c|c|c|c|c|c|c|c|c|}
\hline \multirow[t]{2}{*}{ Clade/gene } & \multirow[t]{2}{*}{$\begin{array}{l}\text { AUC }[95 \% \\
\mathrm{CI}]\end{array}$} & \multirow{2}{*}{$\begin{array}{l}\text { DeLong test } \\
\text { for differ- } \\
\text { ence from } \\
\text { AUC }=0.5 \\
\text { (no discrimi- } \\
\text { nation line): } \\
Z \text { statistic ( } p \\
\text { value) }\end{array}$} & \multirow{2}{*}{$\begin{array}{l}\text { Optimal } \\
\text { threshold } \\
\text { (geqs/mL) }\end{array}$} & \multirow{2}{*}{$\begin{array}{l}\text { True positive } \\
\text { proportion } \\
\text { (sensitivity) } \\
\text { at the optimal } \\
\text { threshold }\end{array}$} & \multirow{2}{*}{$\begin{array}{l}\text { True negative } \\
\text { proportion } \\
\text { (specificity) } \\
\text { at the optimal } \\
\text { threshold }\end{array}$} & \multirow{2}{*}{$\begin{array}{l}\text { Youden's } \\
\text { index at } \\
\text { the optimal } \\
\text { threshold }\end{array}$} & \multicolumn{2}{|c|}{$\begin{array}{l}\text { DeLong test for difference from } \\
\text { sialidase A gene AUC }\end{array}$} \\
\hline & & & & & & & $\begin{array}{l}\text { Difference } \\
{[95 \% \mathrm{CI}]}\end{array}$ & $\begin{array}{l}Z \text { statistic ( } p \\
\text { value) }\end{array}$ \\
\hline Clade 1 & $\begin{array}{l}0.827[0.764- \\
0.891]\end{array}$ & $\begin{array}{l}10.12 \\
(<0.0001)\end{array}$ & $3.4 \times 10^{5}$ & 0.646 & 0.975 & 0.621 & $\begin{array}{l}-0.054 \\
{[-0.100 \text { to }} \\
-0.008]\end{array}$ & $-2.30(0.0216)$ \\
\hline Clade 2 & $\begin{array}{l}0.767[0.700- \\
0.833]\end{array}$ & $7.81(<0.0001)$ & $6.7 \times 10^{4}$ & 0.481 & 0.981 & 0.462 & $\begin{array}{l}-0.115 \\
{[-0.172 \text { to }} \\
-0.058]\end{array}$ & $\begin{array}{r}-3.94 \\
\quad(<0.0001)\end{array}$ \\
\hline Clade 3 & $\begin{array}{l}0.517[0.463- \\
0.570]\end{array}$ & $0.62(0.2865)$ & ND & ND & ND & ND & ND & ND \\
\hline Clade 4 & $\begin{array}{l}0.857[0.797- \\
0.917]\end{array}$ & $\begin{array}{l}11.63 \\
(<0.0001)\end{array}$ & $7.2 \times 10^{5}$ & 0.759 & 0.744 & 0.704 & $\begin{array}{l}-0.024 \\
{[-0.094 \text { to }} \\
0.046]\end{array}$ & $-0.67(0.5031)$ \\
\hline All clades & $\begin{array}{l}0.933[0.890- \\
0.976]\end{array}$ & $\begin{array}{l}19.77 \\
(<0.0001)\end{array}$ & $3.4 \times 10^{6}$ & 0.848 & 0.975 & 0.823 & $\begin{array}{l}0.051[0.005 \\
\text { to } 0.098]\end{array}$ & $2.16(0.0306)$ \\
\hline $\begin{array}{l}\text { Sialidase A } \\
\text { gene }\end{array}$ & $\begin{array}{l}0.881[0.824- \\
0.938]\end{array}$ & $\begin{array}{l}13.05 \\
(<0.0001)\end{array}$ & $2.1 \times 10^{6}$ & 0.734 & 0.981 & 0.716 & & \\
\hline
\end{tabular}

$A U C$ area under the curve, $C I$ confidence interval, $N D$ not determined (because of the marker lacking discriminatory ability for abnormal vaginal microbiota indicating bacterial vaginosis)

of clades 1 and 4 in vaginal specimens, and the abundance of clades varied with different Nugent score, Amsel criteria, and success of treatment.

In a previous study by our group [36], which evaluated a PCR test for diagnosis of BV, significant difference between BV and normal vaginal samples was observed for G. vaginalis clades 1/2 (the PCR assay did not differentiate between clades 1 and 2), 3, and 4 in both detection rates and concentrations, and the presence of multiple clades was strongly associated with higher $G$. vaginalis loads. In our present study, for detection of the G. vaginalis clades we used the PCR assay developed by Balashov et al. [32], for comparability with the previous studies by other groups [32-35].

The most common $G$. vaginalis clade among the Russian women examined in our study was clade $4(94 \%)$, followed by clade $1(56 \%)$, clade $2(40 \%)$, and clade $3(20 \%)$. In concordance with previous studies, although the prevalence figures slightly differed, clades 4 and 1 were the most prevalent $[32,33,35]$. In the present study, G. vaginalis clades 1,2 , and 4 were detected significantly more often and in significantly higher loads in women with BV microbiota than in those with normal vaginal microbiota. Clade 3 showed no association with abnormal microbiota.

Our results confirm that clade multiplicity is strongly associated with abnormal microbiota characteristic of BV. The presence of multiple clades in the vagina might be associated with having multiple sexual partners and engaging in unprotected penile-vaginal sex, which has also been previously suggested [32, 33, 35]. It should also be noted that the G. vaginalis clade multiplicity is consistent with the overall increased microbial diversity associated with abnormal vaginal microbiota. Another reason can be the biofilm character of BV. It is well-recognized that bacteria in BV are frequently present in biofilms, including densely populated microbial communities, which at least partly explains the significantly higher loads of BV-associated bacteria in the vagina of women with $\mathrm{BV}$ than in healthy women. BV biofilm might incorporate different bacteria, including different G. vaginalis strains, over time, so it can be hypothesized that biofilm forms of G. vaginalis in BV are commonly multi clade, whereas dispersed forms of the organism in healthy women are single clade. Furthermore, these multi-clade G. vaginalis biofilms can be transmitted between sexual partners, as shown by Swidsinski et al. [37], who found cohesive $G$. vaginalis forms in all patients with proven BV and their partners using fluorescence in situ hybridization (FISH) analysis. Studies into G. vaginalis forms in normal vaginal and BV samples using clade-specific FISH analysis might help to elucidate this issue.

Sialidase production is considered an important virulence factor in BV and aerobic vaginitis [26, 38], and is associated with adverse pregnancy outcomes [39]. Sialidase is a 
hydrolytic enzyme that degrades protective mucus barriers cleaving sialic acid from terminal glycans of sialoglycoproteins, which are major constituents of mucus [40]. It has been previously demonstrated that not all $G$. vaginalis strains, including those possessing the sialidase gene, produce sialidase [18, 20, 27, 29]. In the present study, the G. vaginalis sialidase A gene was detected in 208 (70\%) women, and its distribution and abundance were strongly associated with abnormal microbiota. Due to the presence of multiple clades in the majority of samples, it was not possible to evaluate the exact frequency of the sialidase A gene in the strains of each G. vaginalis clade. Nevertheless, our results suggest that most clade 4 strains lack the sialidase A gene. Previous analysis of cultured G. vaginalis strains demonstrated the presence of the G. vaginalis sialidase A gene in all clade 1,2 , and 3 strains and in only $3 \%$ of clade 4 strains [29]. Furthermore, in the study by Janulaitiene et al. [33], the G. vaginalis sialidase A gene was detected in all clade 1 and clade 2 isolates, but in none of the clade 4 strains.

Quantification of the loads of the individual G. vaginalis clades and sialidase A gene in the vaginal samples enabled us not only to estimate a difference in those between women with normal microbiota and abnormal microbiota characteristic of $\mathrm{BV}$, but also, using ROC analysis, to investigate if measuring the levels of the G. vaginalis sialidase A gene can differentiate better between normal and BV microbiota than measuring the loads of $G$. vaginalis clades, individually and combined. The AUC value for the sialidase A gene (0.881) significantly exceeded that for clade $1(0.827)$ and $2(0.767)$, but showed no main difference compared with that for clade 4 (0.857) (clade 3 showed no discriminatory capacity for abnormal microbiota). However, the superior AUC value was obtained for the total $G$. vaginalis load (0.933), which was significantly higher than that for the $G$. vaginalis sialidase A gene. Accordingly, the sialidase A gene PCR mostly detects G. vaginalis strains belonging to clades 1, 2, and 3, which are known to contain this gene. However, quantitative detection of all G. vaginalis clades, including clade 4, which appears mostly to lack the sialidase A gene, significantly increased the ability to discriminate between normal and BV microbiota. Thus, in the present study G. vaginalis clade 4 was significantly associated with abnormal vaginal microbiota characteristic of BV. This is in disagreement with the studies by Balashov et al. [32] and Janulaitiene et al. [33], where clade 4 did not relate to BV. This discrepancy can be explained by a higher rate of detection of clade 4 in normal vaginal samples in those studies. Furthermore, in contrast to those studies, we compared not only the distribution but also the abundance of the individual G. vaginalis clades between groups of patients and demonstrated that in the vagina of women with normal microbiota clade 4 was present in significantly lower loads than in women with abnormal microbiota, which was confirmed by the results of our
ROC analysis. It is noteworthy that about $10 \%$ (eight of 79) of all G. vaginalis-positive samples from women with BV microbiota in our study comprised solely clade 4 , with all samples lacking the sialidase A gene. It is not clear whether G. vaginalis clade 4 strains can produce other enzymes with mucinase activity, or if other coexisting BV-associated bacteria possessing sialidase activity, e.g., Prevotella spp., Porphyromonas spp., and Bacteroides spp. [27, 41], can degrade mucin. In the present study, the specimens were not analyzed for phenotypic sialidase activity, which limits the interpretation of our results. Harwich et al. [14] suggested that there is no direct link of sialidase production in $G$. vaginalis with biofilm formation or $\mathrm{BV}$, because both of two investigated G. vaginalis $\mathrm{BV}$ isolates, one sialidase negative and one sialidase positive, had a significantly increased biofilmforming capacity, aggregation, and epithelial cell adherence compared with the non-BV sialidase-negative isolate. This suggestion was recently confirmed by Janulaitiene et al. [42], who found significant difference between G. vaginalis clades 1,2, and 4 in sialidase activity (clade 2 had the highest, clade 1 intermediate, and clade 4 the lowest sialidase activity) but no significant difference between the clades in biofilm-forming ability.

Another limitation of our study is that no data on clinical manifestations specific for BV were available. It should be emphasized that the Nugent scores applied in this study, as well as other laboratory methods for BV diagnosis, reveal abnormal vaginal microbiota, which can be asymptomatic or manifest as the clinical syndrome BV. It cannot be excluded that there were no main symptoms of BV in the women comprising solely sialidase-free $G$. vaginalis strains. Future studies are warranted to verify associations between the presence of the G. vaginalis sialidase A gene, sialidase production, biofilm forming, clinical signs of $\mathrm{BV}$, and $\mathrm{BV}$ recurrence.

It should also be noted that we used the combined loads of the four G. vaginalis clades as a proxy for total G. vaginalis load. This assumption was based on the data of Balashov et al. [32], who validated their clade-specific PCR using 39 cultured G. vaginalis strains and 60 vaginal samples in comparison with three G. vaginalis species-specific PCRs, which targeted the tuf gene [32], the 16S ribosomal RNA (rRNA) gene [43], and the cpn60 gene [44]. All G. vaginalis strains were positive by the PCRs targeting the tuf and $16 \mathrm{~S}$ rRNA genes, and all but one of the G. vaginalis strains were successfully typed by the clade-specific PCR. The cpn60 PCR missed all strains $(n=14)$ typed as clades 2 or 4 by the clade-specific PCR. Of the 60 clinical vaginal samples, 59 were positive for $G$. vaginalis by both the tuf PCR and clade-specific PCR, 58 samples were positive by the $16 \mathrm{~S}$ rRNA PCR, and 44 samples were positive by the cpn60 PCR. These results suggest that the clade-specific PCR detects the large majority of $G$. vaginalis-positive samples. Nevertheless, there are data on a limited sensitivity of this 
clade-specific PCR for the detection of clade 2 and 3 (cpn60 subgroup B and D, respectively) [29]. It is possible that there are molecular variants within the subgroups or additional G. vaginalis subgroups to the four that have already been described. Ideally, only thoroughly validated $G$. vaginalis PCRs proven to detect all G. vaginalis clades/subgroups/ variants should be used for diagnostic purposes.

\section{Conclusions}

The findings of the present study indicate that the detection of all four $G$. vaginalis clades discriminates between normal vaginal microbiota and abnormal vaginal microbiota characteristic of BV more accurately than measuring G. vaginalis sialidase A gene count, and there is a strong association of G. vaginalis clade 4 with BV microbiota, although most of the clade 4 strains appear to lack the sialidase A gene. Our results support previous observations that $G$. vaginalis clades 4 and 1 are the most prevalent in vaginal samples, and clade multiplicity is strongly associated with BV microbiota.

\section{Compliance with Ethical Standards}

Funding The study was supported by the D.O. Ott Research Institute of Obstetrics, Gynaecology and Reproductology, St Petersburg, Russia and the Central Research Institute of Epidemiology, Moscow, Russia. The funders had no role in study design, data collection and analysis, decision to publish, or preparation of the manuscript.

Conflict of interest Elena Shipitsyna, Anna Krysanova, Guzel Khayrullina, Kira Shalepo, Alevtina Savicheva, Alexander Guschin, and Magnus Unemo declare that they have no conflicts of interest that are directly relevant to the content of this study.

Ethical approval The study was approved by the Ethical Committee at the D.O. Ott Research Institute of Obstetrics, Gynaecology and Reproductology, St Petersburg (approval number 73/2015).

Informed consent Informed consent was obtained from all individual participants included in the study.

Open Access This article is distributed under the terms of the Creative Commons Attribution-NonCommercial 4.0 International License (http://creativecommons.org/licenses/by-nc/4.0/), which permits any noncommercial use, distribution, and reproduction in any medium, provided you give appropriate credit to the original author(s) and the source, provide a link to the Creative Commons license, and indicate if changes were made.

\section{References}

1. Koumans EH, Sternberg M, Bruce C, McQuillan G, Kendrick J, Sutton M, et al. The prevalence of bacterial vaginosis in the United States, 2001-2004; associations with symptoms, sexual behaviors, and reproductive health. Sex Transm Dis. 2007;34:864-9.
2. Taylor BD, Darville T, Haggerty CL. Does bacterial vaginosis cause pelvic inflammatory disease? Sex Transm Dis. 2013;40:117-22.

3. Allsworth JE, Peipert JF. Severity of bacterial vaginosis and the risk of sexually transmitted infection. Am J Obstet Gynecol. 2011;205(113):e1-6.

4. Donati L, Di Vico A, Nucci M, Quagliozzi L, Spagnuolo T, Labianca A, et al. Vaginal microbial flora and outcome of pregnancy. Arch Gynecol Obstet. 2010;281:589-600.

5. Denney JM, Culhane JF. Bacterial vaginosis: a problematic infection from both a perinatal and neonatal perspective. Semin Fetal Neonatal Med. 2009;14:200-3.

6. Shipitsyna E, Roos A, Datcu R, Hallén A, Fredlund H, Jensen JS, et al. Composition of the vaginal microbiota in women of reproductive age-sensitive and specific molecular diagnosis of bacterial vaginosis is possible? PLoS One. 2013;8:e60670.

7. Fredricks DN, Fiedler TL, Thomas KK, Oakley BB, Marrazzo JM. Targeted PCR for detection of vaginal bacteria associated with bacterial vaginosis. J Clin Microbiol. 2007;45:3270-6.

8. Alves P, Castro J, Sousa C, Cereija TB, Cerca N. Gardnerella vaginalis outcompetes 29 other bacterial species isolated from BV patients in an in vitro biofilm formation model. J Infect Dis. 2014;210:593-6.

9. Schwebke JR, Muzny C, Josey WE. Role of Gardnerella vaginalis in the pathogenesis of bacterial vaginosis: a conceptual model. J Infect Dis. 2014;210:338-43.

10. Patterson JL, Stull-Lane A, Girerd PH, Jefferson KK. Analysis of adherence, biofilm formation and cytotoxicity suggests a greater virulence potential of Gardnerella vaginalis relative to other bacterial-vaginosis-associated anaerobes. Microbiology. 2010;156:392-9.

11. Piot P, Van Dyck E, Peeters M, Hale J, Totten PA, Holmes KK. Biotypes of Gardnerella vaginalis. J Clin Microbiol. 1984;20:677-9.

12. Benito R, Vazquez JA, Berron S, Fenoll A, Saez-Neito JA. A modified scheme for biotyping Gardnerella vaginalis. J Med Microbiol. 1986;21:357-9.

13. Ingianni A, Petruzzelli S, Morandotti G, Pompei R. Genotypic differentiation of Gardnerella vaginalis by amplified ribosomal DNA restriction analysis (ARDRA). FEMS Immunol Med Microbiol. 1997;18:61-6.

14. Harwich MD, Alves JM, Buck GA, Strauss JF, Patterson JL, Oki AT, et al. Drawing the line between commensal and pathogenic Gardnerella vaginalis through genome analysis and virulence studies. BMC Genom. 2010;11:375.

15. Yeoman CJ, Yildirim S, Thomas SM, Durkin AS, Torralba M, Sutton $\mathrm{G}$, et al. Comparative genomics of Gardnerella vaginalis strains reveals substantial differences in metabolic and virulence potential. PLoS One. 2010;5:e12411.

16. Ahmed A, Earl J, Retchless A, Hillier SL, Rabe LK, Cherpes TL, et al. Comparative genomic analyses of 17 clinical isolates of Gardnerella vaginalis provide evidence of multiple genetically isolated clades consistent with subspeciation into genovars. J Bacteriol. 2012;194:3922-37.

17. Paramel Jayaprakash T, Schellenberg JJ, Hill JE. Resolution and characterization of distinct cpn60-based subgroups of Gardnerella vaginalis in the vaginal microbiota. PLoS One. 2012;7:e43009.

18. Santiago GL, Deschaght P, El Aila N, Kiama TN, Verstraelen H, Jefferson KK, et al. Gardnerella vaginalis comprises three distinct genotypes of which only two produce sialidase. Am J Obstet Gynecol. 2011;204(450):e451-7.

19. Udayalaxmi J, Bhat GK, Kotigadde S. Biotypes and virulence factors of Gardnerella vaginalis isolated from cases of bacterial vaginosis. Indian J Med Microbiol. 2011;29:165-8. 
20. Pleckaityte M, Janulaitiene M, Lasickiene R, Zvirbliene A. Genetic and biochemical diversity of Gardnerella vaginalis strains isolated from women with bacterial vaginosis. FEMS Immunol Med Microbiol. 2012;65:69-77.

21. Castro J, Alves P, Sousa C, Cereija T, França Â, Jefferson KK, et al. Using an in vitro biofilm model to assess the virulence potential of bacterial vaginosis or nonbacterial vaginosis Gardnerella vaginalis isolates. Sci Rep. 2015;5:11640.

22. Schuyler JA, Mordechai E, Adelson ME, Sobel JD, Gygax SE, Hilbert DW. Identification of intrinsically metronidazole-resistant clades of Gardnerella vaginalis. Diagn Microbiol Infect Dis. 2016;84:1-3.

23. Briselden AM, Hillier SL. Longitudinal study of the biotypes of Gardnerella vaginalis. J Clin Microbiol. 1990;28:2761-4.

24. Numanović F, Hukić M, Nurkić M, Gegić M, Delibegović Z, Imamović A, et al. Importance of isolation and biotypization of Gardnerella vaginalis in diagnosis of bacterial vaginosis. Bosn J Basic Med Sci. 2008;8:270-6.

25. Aroutcheva AA, Simoes JA, Behbakht K, Faro S. Gardnerella vaginalis isolated from patients with bacterial vaginosis and from patients with healthy vaginal ecosystems. Clin Infect Dis. 2001;33:1022-7.

26. Lewis WG, Robinson LS, Gilbert NM, Perry JC, Lewis AL. Degradation, foraging, and depletion of mucus sialoglycans by the vagina-adapted Actinobacterium Gardnerella vaginalis. J Biol Chem. 2013;288:12067-79.

27. Briselden AM, Moncla BJ, Stevens CE, Hillier SL. Sialidases (neuraminidases) in bacterial vaginosis and bacterial vaginosisassociated microflora. J Clin Microbiol. 1992;30:663-6.

28. Bradshaw CS, Morton AN, Garland SM, Horvath LB, Kuzevska I, Fairley CK. Evaluation of a point-of-care test, BVBlue, and clini$\mathrm{cal}$ and laboratory criteria for diagnosis of bacterial vaginosis. $\mathrm{J}$ Clin Microbiol. 2005;43:1304-8.

29. Schellenberg JJ, Paramel Jayaprakash T, Withana Gamage N, Patterson MH, Vaneechoutte M, Hill JE. Gardnerella vaginalis subgroups defined by cpn 60 sequencing and sialidase activity in isolates from Canada, Belgium and Kenya. PLoS One. 2016;11:e0146510.

30. Hardy L, Jespers V, Van den Bulck M, Buyze J, Mwambarangwe $\mathrm{L}$, Musengamana $\mathrm{V}$, et al. The presence of the putative Gardnerella vaginalis sialidase A gene in vaginal specimens is associated with bacterial vaginosis biofilm. PLoS One. 2017;12:e0172522.

31. Nugent RP, Krohn MA, Hillier SL. Reliability of diagnosing bacterial vaginosis is improved by a standardized method of gram stain interpretation. J Clin Microbiol. 1991;29:297-301.

32. Balashov SV, Mordechai E, Adelson ME, Gygax SE. Identification, quantification and subtyping of Gardnerella vaginalis in noncultured clinical vaginal samples by quantitative PCR. J Med Microbiol. 2014;63(Pt 2):162-75.

33. Janulaitiene M, Paliulyte V, Grinceviciene S, Zakareviciene J, Vladisauskiene A, Marcinkute A, et al. Prevalence and distribution of Gardnerella vaginalis subgroups in women with and without bacterial vaginosis. BMC Infect Dis. 2017;17:394.

34. Vodstrcil LA, Twin J, Garland SM, Fairley CK, Hocking JS, Law MG, et al. The influence of sexual activity on the vaginal microbiota and Gardnerella vaginalis clade diversity in young women. PLoS One. 2017;12:e0171856.

35. Hilbert DW, Schuyler JA, Adelson ME, Mordechai E, Sobel JD, Gygax SE. Gardnerella vaginalis population dynamics in bacterial vaginosis. Eur J Clin Microbiol Infect Dis. 2017;36:1269-78.

36. Rumyantseva T, Shipitsyna E, Guschin A, Unemo M. Evaluation and subsequent optimizations of the quantitative AmpliSens florocenosis/bacterial vaginosis-FRT multiplex real-time PCR assay for diagnosis of bacterial vaginosis. APMIS. 2016;124:1099-108.

37. Swidsinski A, Doerffel Y, Loening-Baucke V, Swidsinski S, Verstraelen H, Vaneechoutte M, et al. Gardnerella biofilm involves females and males and is transmitted sexually. Gynecol Obstet Investig. 2010;70:256-63.

38. Marconi C, Donders GG, Bellen G, Brown DR, Parada CM, Silva MG. Sialidase activity in aerobic vaginitis is equal to levels during bacterial vaginosis. Eur J Obstet Gynecol Reprod Biol. 2013;167:205-9.

39. Cauci S, Culhane JF. High sialidase levels increase preterm birth risk among women who are bacterial vaginosis-positive in early gestation. Am J Obstet Gynecol. 2011;204:e1-9.

40. Lewis AL, Lewis WG. Host sialoglycans and bacterial sialidases. A mucosal perspective. Cell Microbiol. 2012;14:1174-82.

41. Moncla BJ, Braham P, Hillier SL. Sialidase (neuraminidase) activity among gram-negative anaerobic and capnophilic bacteria. J Clin Microbiol. 1990;28:422-5.

42. Janulaitiene M, Gegzna V, Baranauskiene L, Bulavaitè A, Simanavicius M, Pleckaityte M. Phenotypic characterization of Gardnerella vaginalis subgroups suggests differences in their virulence potential. PLoS One. 2018;13:e0200625.

43. Fredricks DN, Fiedler TL, Thomas KK, Mitchell CM, Marrazzo JM. Changes in vaginal bacterial concentrations with intravaginal metronidazole therapy for bacterial vaginosis as assessed by quantitative PCR. J Clin Microbiol. 2009;47:721-6.

44. Menard JP, Fenollar F, Henry M, Bretelle F, Raoult D. Molecular quantification of Gardnerella vaginalis and Atopobium vaginae loads to predict bacterial vaginosis. Clin Infect Dis. 2008;47:33-43. 